\title{
Developing Evaluation Tool for Mid-Rise Apartments in Pakistan
}

\author{
Alina Babar ${ }^{1}$, Salman Saeed ${ }^{2}$, Mushtaq Ahmad ${ }^{3}$ \\ ${ }^{1}$ Graduate Student, National Institute of Urban Infrastructure Planning, University of Engineering and Technology \\ Peshawar, Pakistan (Email: alinababar1992@gmail.com) \\ ${ }^{2}$ 2Assisstant Professor, National Institute of Urban Infrastructure Planning, University of Engineering and \\ Technology Peshawar, Pakistan (Email: salmansaeed@uetpeshawar.edu.pk) \\ ${ }^{3}$ Graduate Student, National Institute of Urban Infrastructure Planning, University of Engineering and Technology \\ Peshawar, Pakistan (Email: qatshum@gmail.com)
}

\begin{abstract}
Rapid urbanization in major urban centers of Pakistan is leading to the development of multi-story buildings for accommodating growing population and more business. Presently, no safety standards have been followed in multistorey buildings of Pakistan except a few buildings and there is a dire need to regulated the vertical growth in major urban centers of Pakistan
\end{abstract}

This study aims to develop an evaluation System which will evaluate multistory apartments of Pakistan and will promote a well-planned vertical growth. Building Rating System of Pakistan and those used worldwide either focuses on environmental aspects only or not addressing the issues prevalent in Pakistan. The new evaluation system will include all aspects of sustainability as well addressing the local issues and concerns

The methodology used for developing Evaluation system involved collection of Assessment Criteria from literature and then ranking them through expert's survey. Afterwards, Exploratory Factor Analysis technique was adopted to reduce large number of variables in the proposed building rating system by extracting important ones from a large pool as well to identify the new Factor Structure and to give weightage to each item on a rating scale.

Proposed Evaluation system has a total of 230 assessment criteria grouped under 8 main categories for evaluating mid-rise apartments. Weighing analysis of expert survey showed that all criteria are almost equally important and has gained almost equal weightages unlike Green Rating systems in which environmental factors has more weightages in the priority ranking compared to social, economic and other factors.

Key words: Building Rating System, Sustainability, Exploratory Factor Analysis, Mid-rise Apartments.

\section{INTRODUCTION}

\subsection{BACKGROUND}

The population of Pakistan especially of Peshawar and other major urban centers, has doubled since 1998 [2]. This rapid population growth is giving rise to problems like housing shortages and many others. [3]. Developing vertically is seen as solution to make housing available for the growing population.

Besides the benefits of Multistorey Buildings, it has its impacts including adding to the population density and burden on existing infrastructure and others [4]

Multistorey developments are growing rapidly in Peshawar and all over Pakistan but there are barely $1 \%$ Buildings of Peshawar that have followed the safety rules. Building by-laws strictly commends measures for the multistory building to protect inhabitants safety and health but the builders ignore and violate these by-laws while the development authorities fail to ensure the implementation of these by-laws specially ignoring the provision of emergency egress and installation of fire-detection and fire-fighting system giving rise to safety hazards and risking lives of public in case of disaster [1], [4]

The bye-laws are ensured by the developers and authorities during approval of construction drawings but are ignored and violated during construction stage of the building, which in turn affect other services like transport, parking, load on drainage etc. In addition, the firefighting system of Peshawar Rescue Department do not have the power and capacity to extinguish fire at floor higher than 7 where there are buildings higher than 7 floors. [1]

Furthermore, building regulations commends every building to have a car-parking facility in the premises and arrangements for free movement of handicap and elderly population. These requirements have also been ignored in the majority of current multistorey developments [4] 
Alina Babar et al., International Journal of Emerging Trends in Engineering Research, 9(6), June 2021, 748 - 758

Multistorey developments must comply to the prescribed building regulations. Additionally, the impacts of these developments should also be taken care of in order to promote safe developments. This is only possible by developing a system to evaluate existing multistorey developments as well as future developments.

\subsection{RESEARCH PROBLEM}

There are several building evaluation systems e.g., LEED, BREEAM, CASBEE etc. developed for rating the buildings all around the world but these systems rate buildings on percentage of their greenness and mainly focus on environmental aspects of the building while social aspects are given less importance. Similarly, these systems do not address the problems specific to the context of Pakistan

Pakistan has launched a Rating system, SEED, that has been the adaption of LEED. It does not address the local problems either. In addition, existing rating systems do not address the psychological needs, the accessibility of the inhabitants and so on. The main aim of SEED is to reduce the carbon footprint of building and to reduce energy and water consumption irrespective of all other issues common in Pakistan.

A comprehensive Rating System that encompasses all the aspects does not exists both locally and globally

\subsection{OBJECTIVES}

- To list all factors that are important for a Building Rating System

- To filter out factors which cannot be evaluated in the context of Pakistan

- To assign proper weightage to each of factor by incorporating collective wisdom \& experience of relevant experts

\section{METHODOLOGY}

The research process comprised of the following eight steps:

In the 1st step the main assessment criteria i.e., assessment criteria for evaluating existing apartments were identified by reviewing literature on green rating systems used worldwide. Additionally, SEED rating system of Pakistan and GRIHA of India were also reviewed. Other relevant literature was also reviewed for collecting criteria that are given less importance in the Green Rating Systems used worldwide. Furthermore, local newspaper articles regarding vertical developments of Pakistan were also reviewed

In the 2nd and 3rd step, comprehensive list was prepared removing some depending on their local adaptability. A total of 230 assessment criteria that had been collected for evaluating multistory apartments were grouped under 8 main categories as shown in "Table 1" below

In the 4th and 5th step, a survey form was established and responses were collected from 300 Professionals in relevant fields. The purpose of the survey form was to rank and score assessment criteria on a 5-point Likert scale through expert's survey. Moreover, the questionnaire was face validated by involving experts who were familiar with the research topic and also with questionnaire construction prior to expert's survey.

In the 6th step, the responses were entered into spreadsheet for data cleaning through removing inconsistent respondents and incomplete questionnaires.

In the 7th step, Exploratory Factor Analysis was performed on the data set to calculate weights and to identify Factor structure. SPSS had been used for conducting Exploratory Factor Analysis. EFA ensures whether assessment criteria that measures the similar issue, load on the similar factors. EFA uses Factor Loading to combine criteria that load on the same factors. Factor loading shows which factors are being measured by which criteria. It groups variables that has strong correlations. It ranges from -1 to 1 . Factor loading value higher than \pm 0.6 is recommended while grouping factors [5]-[8].

In the final 8th step, the Factor Loads estimated under EFA was then standardized to final 100 points score of each category on the rating scale.

Table 1:List of Identified Assessment Criteria \& Factor Structure

\begin{tabular}{|c|l|c|c|}
\hline No. & Categories & Factors & Assessment Criteria \\
\hline 1. & Resource Saving \& Waste Prevention & 6 Factors & 23 Criteria \\
\hline 2. & Comfortable \& Healthy Indoor Environment & 9 Factors & 40 Criteria \\
\hline 3. & Visual Comfort in Indoor Environment & 3 Factors & 16 Criteria \\
\hline 4. & Health \& Fitness & 5 Factors & 26 Criteria \\
\hline 5. & Safety \& Security & 6 Factors & 31 Criteria \\
\hline 6. & Building Operation \& Services & 5 Factors & 23 Criteria \\
\hline 7. & Space Utilization \& Adaptability & 7 Factors & 36 Criteria \\
\hline 8. & Consideration of Local \& Global Environment & 7 Factors & 35 Criteria \\
\hline & & 48 Factors & 230 Criteria \\
\hline
\end{tabular}




\section{RESULTS}

EFA was conducted on each of the 8 categories individually to determine the Factor structure (i.e., to group assessment criteria under each category) as well to assign weights to each item on the rating scale.

The data was analyzed using SPSS Factor Analysis technique with Promax (Oblique Rotation) and Maximum Likelihood (Extraction) to determine the factor structure as well to assign weights

Factors are extracted based on their eigen values. Components that have Eigen Values $\geq 1$ are selected because 1 is the average eigenvalue and $>1$ means higher than average [9]. The eigenvalue is a number telling us how spread out the data is on the line [10]. Variables that are related are combined to extract few factors.

Factors are rotated to help interpret results. Factor rotation is often needed for interpreting results because it makes the factor loads to be more clearly differentiated [11].

There are two basic types of rotation: orthogonal rotations \& oblique rotations. Orthogonal rotation assumes that the factors not correlated with one another and impose the restriction that the factors cannot be correlated whereas Oblique rotation extracts factor loads by assuming that the factors are correlated. Oblique rotation obtains both the factor loadings and the correlation between factors [7]. The variables are assessed for the unique interdependence between each factor and the variables [11].

This study has used Promax of oblique rotation's method. Promax is used for large datasets. It is calculated faster than Direct Oblimin method. This method is used in cases where the researcher is unsure of the rotation method that needs to be used [11].

The factor structure of each category and the weightages of each assessment criteria under each category is shown below:

\subsection{INITIAL WEIGHTS\& STANDARD WEIGHTS}

The Initial weights given in below tables are extracted in the form of Factor Loadings during Exploratory Factor Analysis

Afterwards, the weights were standardized to 100 using the following formula: $X=100$ / Sum of all Weights

And then multiplying " $X$ " by un-standardized weight of each criterion to get Standard Weight, the sum of which will we 100 . The same process is repeated for each category

The Sum of Weightages of Factors under each Main Category is Equal to 100

\subsubsection{RESOURCE SAVING \& WASTE PREVENTION}

Sum of un-standardized Weights of all Variables $=14.008$

Using Formula: $100 / 14.008=7.14$

Now multiplying "7.14" by unstandardized weight of each variable to get the standard weights given in the "Table 2".

Table 2: Weightages of Factors \& Criteria of "Resource Saving \& Waste Prevention"

\begin{tabular}{|c|c|c|c|c|}
\hline Factors & Assessment Criteria & Initial Weights & Standard Weights & $\Sigma$ Weights \\
\hline \multirow{7}{*}{ Factor 1} & $\begin{array}{l}\text { Recycled materials used for ground reinforcement and } \\
\text { foundations }\end{array}$ & 0.902 & 6.4 & \multirow{7}{*}{33.1} \\
\hline & Reused Exterior Building Materials & 0.753 & 5.4 & \\
\hline & Continuing Use of Existing Building Skeleton & 0.74 & 5.3 & \\
\hline & Recycled concrete frame building & 0.7 & 5.0 & \\
\hline & Use of recycled materials for external area & 0.583 & 4.2 & \\
\hline & Efforts to Enhance the Reusability of Components and Materials & 0.496 & 3.5 & \\
\hline & Provision of information on materials used & 0.46 & 3.3 & \\
\hline \multirow{5}{*}{ Factor 2} & Highly energy-efficient equipment & 0.694 & 5.0 & \multirow{5}{*}{20.0} \\
\hline & Natural Energy Utilization & 0.676 & 4.8 & \\
\hline & Ventilation system & 0.545 & 3.9 & \\
\hline & Water Saving systems & 0.467 & 3.3 & \\
\hline & Energy Saving Lightings & 0.424 & 3.0 & \\
\hline \multirow{4}{*}{ Factor 3} & Gray Water Reuse System & 0.616 & 4.4 & \multirow{4}{*}{14.8} \\
\hline & Responsive Light Control & 0.524 & 3.7 & \\
\hline & Rainwater Reuse System & 0.512 & 3.7 & \\
\hline & Monitoring \& control of energy & 0.428 & 3.1 & \\
\hline \multirow{4}{*}{ Factor 4} & Energy Efficient Cooling system & 0.665 & 4.7 & \multirow{4}{*}{16.0} \\
\hline & Energy Efficient Heating system & 0.633 & 4.5 & \\
\hline & Efficiency in Entire Service System of Building & 0.504 & 3.6 & \\
\hline & Reducing building heating demand & 0.446 & 3.2 & \\
\hline \multirow{2}{*}{ Factor 5} & Energy Saving home electric appliances and kitchen equipment & 0.982 & 7.0 & \multirow[b]{2}{*}{9.9} \\
\hline & Hot-water supply equipment & 0.401 & 2.9 & \\
\hline Factor 6 & Reused Interior Building Materials & 0.857 & 6.1 & 6.1 \\
\hline & Weight Sum & 14.008 & 100.0 & 100.0 \\
\hline
\end{tabular}


Alina Babar et al., International Journal of Emerging Trends in Engineering Research, 9(6), June 2021,748 - 758

\subsubsection{COMFORTABLE \& HEALTHY INDOOR ENVIRONMENT}

Sum of un-standardized Weights of all Variables $=24.812$

Using Formula: $100 / 24.81=4.03$

Now multiplying "4.03" by unstandardized weight of each variable to get the standard weights given in the "Table 3" below

Table 3: Weightages of Factors \& Variables of "Comfortable \& Healthy Indoor Environment"

\begin{tabular}{|c|c|c|c|c|}
\hline Factors & Assessment Criteria & Initial Weights & Standard Weights & $\Sigma$ Weights \\
\hline \multirow{10}{*}{ Factor 1} & Exterior Liquid Water Management & 0.924 & 3.72 & \multirow{10}{*}{26.43} \\
\hline & Interior Liquid Water Management & 0.784 & 3.16 & \\
\hline & Condensation Management & 0.773 & 3.12 & \\
\hline & Entryway Air Seal & 0.721 & 2.91 & \\
\hline & Moisture Resistant Materials & 0.655 & 2.64 & \\
\hline & Appliance \& Heater Combustion Ban & 0.646 & 2.60 & \\
\hline & Control of Smoking Indoor & 0.624 & 2.51 & \\
\hline & Source Control & 0.575 & 2.32 & \\
\hline & Maintaining Relative Humidity through HVAC & 0.472 & 1.90 & \\
\hline & Entryway Walk-Off Systems & 0.384 & 1.55 & \\
\hline \multirow{8}{*}{ Factor 2} & Cleaning Equipment & 0.988 & 3.98 & \multirow{8}{*}{20.23} \\
\hline & Storage of Chemical Cleaning Agents & 0.732 & 2.95 & \\
\hline & Cleanable Environment & 0.728 & 2.93 & \\
\hline & Easily Cleanable Material & 0.702 & 2.83 & \\
\hline & Radiant Heating System & 0.642 & 2.59 & \\
\hline & Demand control ventilation & 0.505 & 2.04 & \\
\hline & Adequacy of opening for Natural Ventilation & 0.38 & 1.53 & \\
\hline & Asbestos Control & 0.343 & 1.38 & \\
\hline \multirow{6}{*}{ Factor 3} & Sunlight adjustment capability & 0.716 & 2.89 & \multirow{6}{*}{13.80} \\
\hline & Ventilation Rate & 0.656 & 2.64 & \\
\hline & Allowing breezes in and heat out & 0.644 & 2.60 & \\
\hline & Consideration for Outside Air Intake & 0.491 & 1.98 & \\
\hline & Proper Zoning for olfactory comfort & 0.484 & 1.95 & \\
\hline & Direct Source Ventilation & 0.434 & 1.75 & \\
\hline \multirow{5}{*}{ Factor 4} & $\begin{array}{l}\text { Sound Insulation Performance of Floor Slabs w.r.t Light Weight } \\
\text { Impact Source }\end{array}$ & 0.811 & 3.27 & \multirow{5}{*}{12.09} \\
\hline & $\begin{array}{l}\text { Sound Insulation Performance of Floor Slabs w.r.t Heavy Weight } \\
\text { Impact Source }\end{array}$ & 0.757 & 3.05 & \\
\hline & Sound Absorbing materials to limit reverberation time & 0.582 & 2.35 & \\
\hline & Sound Insulation of Partition Walls and Doors & 0.524 & 2.11 & \\
\hline & Indoor Air Monitors & 0.325 & 1.31 & \\
\hline \multirow{4}{*}{ Factor 5} & Ensuring thermal insulation airtightness performance & 0.7 & 2.82 & \multirow{4}{*}{9.80} \\
\hline & Maintaining Room Temperature & 0.692 & 2.79 & \\
\hline & Air conditioning zoning & 0.633 & 2.55 & \\
\hline & Standard Level of Radon Gas & 0.407 & 1.64 & \\
\hline \multirow[t]{2}{*}{ Factor 6} & $\begin{array}{l}\text { Sound Insulation of Exterior wall Openings for Preventing } \\
\text { Exterior noise intrusion }\end{array}$ & 0.686 & 2.76 & \multirow[t]{2}{*}{4.38} \\
\hline & Acoustic Planning to maintain allowable indoor sound levels & 0.402 & 1.62 & \\
\hline Factor 7 & Air Infiltration Management & 0.95 & 3.83 & 3.83 \\
\hline \multirow{2}{*}{ Factor 8} & Pest Inspection \& Reduction & 0.832 & 3.35 & \multirow[b]{2}{*}{5.30} \\
\hline & Microbe \& Mold Control & 0.484 & 1.95 & \\
\hline \multirow{2}{*}{ Factor 9} & Air Filtration & 0.689 & 2.78 & \multirow[b]{2}{*}{4.13} \\
\hline & Standards for Particulate Matter and Inorganic Gases & 0.335 & 1.35 & \\
\hline & Weight Sum & 24.812 & 100.00 & 100.00 \\
\hline
\end{tabular}


Alina Babar et al., International Journal of Emerging Trends in Engineering Research, 9(6), June 2021,748 - 758

\subsubsection{VISUAL COMFORT IN INDOOR ENVIRONMENT}

Sum of un-standardized Weights of all Variables $=9.992$

Using Formula: $100 / 9.992=10.01$

Now multiplying "10.01" by unstandardized weight of each variable to get the standard weights given in the "Table 4" below

Table 4: Weightages of Factors \& Variables of "Visual Comfort in Indoor Environment"

\begin{tabular}{|c|c|c|c|c|}
\hline Factors & Assessment Criteria & Initial Weights & Standard Weights & $\Sigma$ Weights \\
\hline \multirow{10}{*}{ Factor 1} & Automated shading devices for sunlight control & 0.887 & 8.88 & \multirow{10}{*}{62.42} \\
\hline & Light reflectivity of surfaces for controlling glare & 0.885 & 8.86 & \\
\hline & $\begin{array}{l}\text { Controlling Glare from Light Fixtures through Luminaire } \\
\text { Shielding }\end{array}$ & 0.84 & 8.41 & \\
\hline & $\begin{array}{l}\text { Solar glare control through window shading \& Light } \\
\text { Management }\end{array}$ & 0.659 & 6.60 & \\
\hline & Light Elimination at Night & 0.625 & 6.26 & \\
\hline & Circadian lighting design & 0.573 & 5.73 & \\
\hline & Motion-activated Nighttime Interior Lighting & 0.551 & 5.51 & \\
\hline & Lighting Controllability & 0.487 & 4.87 & \\
\hline & $\begin{array}{l}\text { Brightness contrast between spaces while maintaining luminance } \\
\text { variety }\end{array}$ & 0.367 & 3.67 & \\
\hline & Daylight Devices & 0.363 & 3.63 & \\
\hline \multirow{2}{*}{ Factor 2} & Percentage of opening for Daylight -Window Sizes & 1.016 & 10.17 & \multirow[b]{2}{*}{15.48} \\
\hline & Daylight Factor & 0.531 & 5.31 & \\
\hline \multirow{4}{*}{ Factor 3} & Window Transmittance & 0.955 & 9.56 & \multirow{4}{*}{22.10} \\
\hline & Openings by Orientation & 0.443 & 4.43 & \\
\hline & Maintaining accurate Color Quality & 0.416 & 4.16 & \\
\hline & Illuminance Level OR Maintaining required intensity & 0.394 & 3.94 & \\
\hline & Weight Sum & 9.992 & 100.00 & 100.00 \\
\hline
\end{tabular}


Alina Babar et al., International Journal of Emerging Trends in Engineering Research, 9(6), June 2021,748 - 758

\subsubsection{HEALTH \& FITNESS}

Sum of un-standardized Weights of all Variables $=17.03$

Using Formula: $100 / 17.03=5.87$

Now multiplying " 5.87 " by unstandardized weight of each variable to get the standard weights given in the "Table 5" below

Table 5: Weightages of Factors \& Variables of "Health and Fitness"

\begin{tabular}{|c|c|c|c|c|}
\hline Factors & Assessment Criteria & Initial Weights & Standard Weights & $\Sigma$ Weights \\
\hline \multirow{7}{*}{ Factor 1} & Active Transportation Support & 0.74 & 4.46 & \multirow{7}{*}{26.38} \\
\hline & Children's Play & 0.716 & 4.32 & \\
\hline & Neighborhood Connectivity & 0.706 & 4.26 & \\
\hline & Indoor Leisure or Sports Facilities & 0.644 & 3.88 & \\
\hline & Outdoor Leisure or Sports Facilities & 0.598 & 3.60 & \\
\hline & Facilities for aged & 0.51 & 3.07 & \\
\hline & Window Access & 0.463 & 2.79 & \\
\hline \multirow{4}{*}{ Factor 2} & Inorganic contaminants - Dissolved Metals Removal & 0.982 & 5.92 & \multirow{4}{*}{18.59} \\
\hline & Water Turbidity \& Coliform Removal & 0.84 & 5.06 & \\
\hline & Organic contaminant Removal & 0.815 & 4.91 & \\
\hline & Agricultural contaminants Removal & 0.447 & 2.69 & \\
\hline \multirow{6}{*}{ Factor 3} & Pedestrian Promotion & 0.681 & 4.11 & \multirow{6}{*}{21.09} \\
\hline & Access to drinking Water & 0.649 & 3.91 & \\
\hline & Pedestrian Facility & 0.632 & 3.81 & \\
\hline & Community Amenity Space & 0.612 & 3.69 & \\
\hline & Participation of building occupants & 0.554 & 3.34 & \\
\hline & Stair Use Promotion & 0.37 & 2.23 & \\
\hline \multirow{5}{*}{ Factor 4} & Nature Incorporation & 0.954 & 5.75 & \multirow{5}{*}{18.74} \\
\hline & Universal design of outdoor space & 0.728 & 4.39 & \\
\hline & Incorporating natures patterns & 0.608 & 3.67 & \\
\hline & Outdoor Natural Environment & 0.463 & 2.79 & \\
\hline & Allocating Housing Units to Low-income Group & 0.356 & 2.15 & \\
\hline \multirow{4}{*}{ Factor 5} & Legionella Control & 0.766 & 4.62 & \multirow{4}{*}{15.20} \\
\hline & Public water additives & 0.68 & 4.10 & \\
\hline & Water Dispenser Maintenance & 0.628 & 3.79 & \\
\hline & Quarterly water quality testing \& Record Keeping & 0.447 & 2.69 & \\
\hline & Q & 16.589 & 100.00 & 100.00 \\
\hline
\end{tabular}


Alina Babar et al., International Journal of Emerging Trends in Engineering Research, 9(6), June 2021,748 - 758

\subsubsection{SAFETY \& SECURITY}

Sum of un-standardized Weights of all Variables $=18.85$

Using Formula: $100 / 18.85=5.31$

Now multiplying "5.31" by unstandardized weight of each variable to get the standard weights given in the "Table 6" below

Table 6: Weightages of Factors \& Variables of "Safety and Security"

\begin{tabular}{|c|c|c|c|c|}
\hline Factors & Assessment Criteria & Initial Weights & Standard Weights & $\Sigma$ Weights \\
\hline \multirow{6}{*}{ Factor 1} & Egress Plan \& Training & 0.939 & 4.98 & \multirow{6}{*}{22.63} \\
\hline & Exit Discharge & 0.859 & 4.56 & \\
\hline & Emergency Access \& Signage & 0.719 & 3.81 & \\
\hline & First Aid Kits & 0.717 & 3.80 & \\
\hline & Emergency Exit & 0.596 & 3.16 & \\
\hline & Monthly Testing of safety Equipment and record keeping & 0.436 & 2.31 & \\
\hline \multirow{5}{*}{ Factor 2} & Fire-resistant structure & 1.221 & 6.48 & \multirow{5}{*}{19.10} \\
\hline & Seismic Resistant structure & 0.946 & 5.02 & \\
\hline & Crime prevention in spaces outside building & 0.628 & 3.33 & \\
\hline & Egress Court & 0.403 & 2.14 & \\
\hline & Fire Fighting system & 0.402 & 2.13 & \\
\hline \multirow{8}{*}{ Factor 3} & Electronic Access Control System & 0.976 & 5.18 & \multirow{8}{*}{23.22} \\
\hline & Limiting number of access and exit & 0.718 & 3.81 & \\
\hline & Intruder alarms & 0.543 & 2.88 & \\
\hline & Perimeter protection & 0.487 & 2.58 & \\
\hline & HVAC System & 0.455 & 2.41 & \\
\hline & Fall protection equipment & 0.441 & 2.34 & \\
\hline & Pedestrian Paths & 0.385 & 2.04 & \\
\hline & Zebra crossing & 0.372 & 1.97 & \\
\hline \multirow{7}{*}{ Factor 4} & Communications \& IT Equipment & 0.808 & 4.29 & \multirow{7}{*}{19.38} \\
\hline & Sufficient exterior illumination & 0.664 & 3.52 & \\
\hline & Support Method of Machines \& Ducts & 0.575 & 3.05 & \\
\hline & Emergency Refugee Areas & 0.514 & 2.73 & \\
\hline & Electrical Equipment & 0.434 & 2.30 & \\
\hline & Water Supply \& Drainage & 0.351 & 1.86 & \\
\hline & High Fire-resistant plants & 0.308 & 1.63 & \\
\hline \multirow{2}{*}{ Factor 5} & Preventing Intrusion through Windows & 0.611 & 3.24 & \multirow{2}{*}{6.41} \\
\hline & Security Guards & 0.598 & 3.17 & \\
\hline \multirow{3}{*}{ Factor 6} & Hand-Handled Fire Safety Equipment & 0.966 & 5.12 & \multirow{3}{*}{9.25} \\
\hline & CCTV cameras & 0.469 & 2.49 & \\
\hline & Fire Detection System & 0.309 & 1.64 & \\
\hline & Weight Sum & 18.85 & 100.00 & 100.00 \\
\hline
\end{tabular}


Alina Babar et al., International Journal of Emerging Trends in Engineering Research, 9(6), June 2021,748 - 758

\subsubsection{BUILDING OPERATION \& SERVICES}

Sum of un-standardized Weights of all Variables $=13.33$

Using Formula: $100 / 13.33=7.50$

Now multiplying "7.50" by unstandardized weight of each variable to get the standard weights given in the "Table 7" below

Table 7: Weightages of Factors \& Variables of "Building Operation \& Services"

\begin{tabular}{|c|c|c|c|c|}
\hline Factors & Assessment Criteria & Initial Weights & Standard Weights & $\Sigma$ Weights \\
\hline \multirow{8}{*}{ Factor 1} & Service Life of Roof materials & 0.794 & 5.96 & \multirow{8}{*}{32.94} \\
\hline & Service Life of Structural Frame Materials & 0.778 & 5.84 & \\
\hline & Television Transmission & 0.605 & 4.54 & \\
\hline & Maintenance cost of building & 0.555 & 4.16 & \\
\hline & Necessary Renewal Interval for Main Interior Finishes & 0.5 & 3.75 & \\
\hline & Storage facilities for Bulky Waste & 0.417 & 3.13 & \\
\hline & Ease of Waste Disposal by Residents & 0.417 & 3.13 & \\
\hline & Durability of windows against wind and rain & 0.325 & 2.44 & \\
\hline \multirow{5}{*}{ Factor 2} & Use of Advanced Information System & 0.795 & 5.96 & \multirow{5}{*}{22.29} \\
\hline & Building integrated management system & 0.677 & 5.08 & \\
\hline & Electronic Facility & 0.643 & 4.82 & \\
\hline & Ensuring Functionality of Maintenance System & 0.523 & 3.92 & \\
\hline & $\begin{array}{l}\text { Necessary Replacement Interval for Air Conditioning and } \\
\text { Ventilation Ducts }\end{array}$ & 0.333 & 2.50 & \\
\hline \multirow{5}{*}{ Factor 3} & Necessary Renewal Interval for Major Equipment \& Services & 1.099 & 8.24 & \multirow{5}{*}{20.17} \\
\hline & Necessary Renewal Interval for HVAC and Water Pipes & 0.499 & 3.74 & \\
\hline & Ease of maintenance of the piping of building & 0.399 & 2.99 & \\
\hline & Necessary Repair Interval for Exterior Finishes & 0.385 & 2.89 & \\
\hline & Mailing services & 0.307 & 2.30 & \\
\hline \multirow{3}{*}{ Factor 4} & On-site Waste Accumulation, Handling \& Storage & 0.975 & 7.31 & \multirow{3}{*}{13.90} \\
\hline & Waste Segregation at source & 0.53 & 3.98 & \\
\hline & Waste management Training & 0.348 & 2.61 & \\
\hline \multirow{2}{*}{ Factor 5} & Inspections \& Maintenance Awareness & 1.025 & 7.69 & \multirow{2}{*}{10.70} \\
\hline & Design which considers Maintenance & 0.401 & 3.01 & \\
\hline & Weight Sum & 13.33 & 100.00 & 100.00 \\
\hline
\end{tabular}


Alina Babar et al., International Journal of Emerging Trends in Engineering Research, 9(6), June 2021,748 - 758

\subsubsection{SPACE UTILIZATION \& ADAPTABILITY}

Sum of un-standardized Weights of all Variables $=21.302$

Using Formula: $100 / 21.302=4.69$

Now multiplying " 4.69 " by unstandardized weight of each variable to get the standard weights given in the "Table 8 " below

Table 8: Weightages of Factors \& Variables of "Space Utilization \& Adaptability"

\begin{tabular}{|c|c|c|c|c|}
\hline Factors & Assessment Criteria & Initial Weights & Standard Weights & $\Sigma$ Weights \\
\hline \multirow{9}{*}{ Factor 1} & Flexibility in of Floor Layout & 0.846 & 3.97 & \multirow{9}{*}{24.75} \\
\hline & Private Amenity Space & 0.83 & 3.90 & \\
\hline & Incorporating Aesthetic Elements in Common Spaces & 0.763 & 3.58 & \\
\hline & Provision of Backup Space & 0.642 & 3.01 & \\
\hline & Floor Load Margin & 0.58 & 2.72 & \\
\hline & Spatial Familiarity & 0.551 & 2.59 & \\
\hline & Ease of Equipment Renewal & 0.36 & 1.69 & \\
\hline & More freedom in layout of fixtures \& Furniture & 0.35 & 1.64 & \\
\hline & Garbage Storage within apartments & 0.35 & 1.64 & \\
\hline \multirow{6}{*}{ Factor 2} & Storage for building supplies & 0.769 & 3.61 & \multirow{6}{*}{19.03} \\
\hline & Plant Rooms/ Mechanical, Electrical \& Plumbing Room & 0.733 & 3.44 & \\
\hline & Generator Room & 0.68 & 3.19 & \\
\hline & Service Elevators & 0.665 & 3.12 & \\
\hline & Communal Drying Spaces & 0.634 & 2.98 & \\
\hline & Services Ducts & 0.572 & 2.69 & \\
\hline \multirow{6}{*}{ Factor 3} & Ease of Water Supply and Drain Pipe Renewal & 1.056 & 4.96 & \multirow{6}{*}{16.79} \\
\hline & Ease of Air Conditioning Duct Renewal & 0.706 & 3.31 & \\
\hline & Ease of Electrical Wiring Renewal & 0.644 & 3.02 & \\
\hline & Ease of Communications Cable Renewal & 0.47 & 2.21 & \\
\hline & Circulation of corridor & 0.384 & 1.80 & \\
\hline & Adequacy of ceiling height & 0.317 & 1.49 & \\
\hline \multirow{5}{*}{ Factor 4} & Allowance for Floor-to-floor Height & 0.555 & 2.61 & \multirow{5}{*}{10.80} \\
\hline & Staircase Design Considerations & 0.479 & 2.25 & \\
\hline & Stair Accessibility & 0.451 & 2.12 & \\
\hline & Aesthetically pleasing Façade & 0.426 & 2.00 & \\
\hline & Child-care facility & 0.389 & 1.83 & \\
\hline \multirow{6}{*}{ Factor 5} & Janitor's closets & 0.828 & 3.89 & \multirow{6}{*}{14.79} \\
\hline & Rooms for cleaning staff & 0.753 & 3.53 & \\
\hline & Building offices & 0.45 & 2.11 & \\
\hline & Barrier-free Planning & 0.382 & 1.79 & \\
\hline & ICT Room & 0.381 & 1.79 & \\
\hline & Control Room & 0.356 & 1.67 & \\
\hline \multirow{2}{*}{ Factor 6} & Privacy from neighborhood & 0.98 & 4.60 & \multirow{2}{*}{6.96} \\
\hline & Size of rooms & 0.503 & 2.36 & \\
\hline \multirow{2}{*}{ Factor 7} & Adequacy of storage space & 0.994 & 4.67 & \multirow{2}{*}{6.89} \\
\hline & Adequacy of parking area & 0.473 & 2.22 & \\
\hline & Weight Sum & 21.302 & 100.00 & 100.00 \\
\hline
\end{tabular}


Alina Babar et al., International Journal of Emerging Trends in Engineering Research, 9(6), June 2021,748 - 758

\subsubsection{CONSIDERATION OF LOCAL \& GLOBAL ENVIRONMENT}

Sum of un-standardized Weights of all Variables $=20.516$

Using Formula: $100 / 20.516=4.87$

Now multiplying "4.87" by unstandardized weight of each variable to get the standard weights given in the "Table 9" below

Table 9: Weightages of Factors \& Variables of "Consideration of Local \& Global Environment"

\begin{tabular}{|c|c|c|c|c|}
\hline Factors & Assessment Criteria & Initial Weights & Standard Weights & $\Sigma$ Weights \\
\hline \multirow{8}{*}{ Factor 1} & Controlling Gas Concentrations at Source & 0.972 & 4.74 & \multirow{8}{*}{23.90} \\
\hline & Sand \& Dust Control & 0.847 & 4.13 & \\
\hline & Prevent Exhaust generated from affecting neighboring Buildings & 0.632 & 3.08 & \\
\hline & Control of Smoking Outdoor & 0.618 & 3.01 & \\
\hline & Vehicle Engine Exhaust Reduction & 0.601 & 2.93 & \\
\hline & $\mathrm{CO}_{2}$ Monitoring & 0.443 & 2.16 & \\
\hline & Outdoor Illumination \& Light that Spills from Interiors & 0.409 & 1.99 & \\
\hline & Facilitating Air Flow toward Downwind Areas & 0.382 & 1.86 & \\
\hline \multirow{6}{*}{ Factor 2} & Prevent sources of Noise from affecting neighborhood & 0.855 & 4.17 & \multirow{6}{*}{20.21} \\
\hline & Preservation of Habitat & 0.822 & 4.01 & \\
\hline & Sewage Load Suppression & 0.725 & 3.53 & \\
\hline & Waste Treatment Loads & 0.707 & 3.45 & \\
\hline & Controlling Foul Odor & 0.644 & 3.14 & \\
\hline & Prevent sources of Vibrations from affecting neighborhood & 0.394 & 1.92 & \\
\hline \multirow{6}{*}{ Factor 3} & Greening of the premises & 0.765 & 3.73 & \multirow{6}{*}{17.42} \\
\hline & Management of Conserved or Created Green Spaces & 0.759 & 3.70 & \\
\hline & Creation of Biotope & 0.664 & 3.24 & \\
\hline & Cleanliness of public space & 0.539 & 2.63 & \\
\hline & $\begin{array}{l}\text { Harmony of building design with surrounding Townscape \& } \\
\text { Landscape }\end{array}$ & 0.459 & 2.24 & \\
\hline & Harmony of Building's Green Space with surrounding Landscape & 0.387 & 1.89 & \\
\hline \multirow{5}{*}{ Factor 4} & Mitigating Reflected Solar Glare from Building Walls & 0.884 & 4.31 & \multirow{5}{*}{12.62} \\
\hline & Countermeasures against light pollution from billboard lighting & 0.535 & 2.61 & \\
\hline & Outdoor Air Monitors & 0.448 & 2.18 & \\
\hline & $\begin{array}{l}\text { Elimination of CFCs and Halons used in Fire Retardants, Insulation } \\
\text { Materials \& Refrigerants }\end{array}$ & 0.384 & 1.87 & \\
\hline & Reducing Life Cycle CO2 emission rate & 0.339 & 1.65 & \\
\hline \multirow{5}{*}{ Factor 5} & Considering Building Cladding Materials & 0.773 & 3.77 & \multirow{5}{*}{13.62} \\
\hline & Consider Ground Surface Coverage & 0.574 & 2.80 & \\
\hline & Attention to Local Character, Culture \& History & 0.533 & 2.60 & \\
\hline & Creating Shade from sun at site to Prevent Heat Accumulation & 0.512 & 2.50 & \\
\hline & Reduce Heat Emissions from Building Equipment & 0.402 & 1.96 & \\
\hline \multirow{3}{*}{ Factor 6} & Low-emission Combustors to reduce $\mathrm{CO} 2$ Concentrations & 0.595 & 2.90 & \multirow{3}{*}{6.92} \\
\hline & Traffic Load Control & 0.42 & 2.05 & \\
\hline & Reduction of Rainwater Discharge Load & 0.404 & 1.97 & \\
\hline \multirow{2}{*}{ Factor 7} & Preliminary Investigation of Local Heat Environment & 0.638 & 3.11 & \multirow[b]{2}{*}{5.31} \\
\hline & Restriction of daylight obstruction & 0.451 & 2.20 & \\
\hline & Weight Sum & 20.516 & 100.00 & 100.00 \\
\hline
\end{tabular}


Alina Babar et al., International Journal of Emerging Trends in Engineering Research, 9(6), June 2021, 748 - 758

\section{CONCLUSIONS}

This research has collected and combined factors from exiting rating systems used worldwide and factors that are mentioned in other literature. It also includes factors that are not mentioned in other literature but were prevalent in the locality.

A total of 230 assessment criteria had been finalized for evaluating mid-rise residential buildings and were associated with 8 Main Categories and were further assigned to 48 sub-categories known as factors for more detailed categorization.

Weighing analysis of expert survey showed that all criteria are almost equally important and has gained almost equal weightages unlike Green Rating systems in which environmental factors has more weightages in the priority ranking compared to social, economic and other factors.

\section{ACKNOWLEDGMENTS}

I would like to express my special thanks of gratitude to my supervisor, Dr. Salman Saeed" who gave me a golden opportunity to work on this project on the topic; which also helped me in doing a lot of research and I came to know about so many new things. I am really thankful to him.

Secondly, I would like to thank my parents, my siblings and my fiancé who supported me morally which instead helped me in finalizing this project with in the limited time frame

Lastly, there has been no significant financial support for this work that is, this research did not receive any specific grant from funding agencies in the public, commercial, or not-for-profit sectors.

CONFLICT OF INTEREST: The authors declare that they have no known competing financial interests or personal relationships that could have appeared to influence the work reported in this paper.

\section{REFERENCES}

[1] Z. Ali, "Safety rules ignored in Peshawar high-rises," Dawn, Jul. 25, 2013.
[2] I. Ullah, "Peshawar records highest population growthamong all K-P divisions," THE EXPRESS TRIBUNE, 2017.

[3] Tasneem Siddiqui, "Urbanization,Housing for Low-Income," no. January, pp. 1-6, 2014.

[4] S. Akbar, "Building laws violations threaten safety of citizens in Peshawar," News Lens, 2016.

[5] UCLA: Statistical Consulting Group, "A Practical Introduction to Factor Analysis," newtest: command to compute new test @ ONLINE, 2011. https://stats.idre.ucla.edu/spss/seminars/introduction-to-factor -analysis/a-practical-introduction-to-factor-analysis/.

[6] L. Moutinho, G. Hutcheson, and L. Moutinho, "Exploratory or Confirmatory Factor Analysis," SAGE Dict. Quant. Manag. Res., pp. 111-116, 2014, doi: 10.4135/9781446251119.n34.

[7] Newsom, "A Quick Primer on Exploratory Factor Analysis," Johns Hopkins University, pp. 1-4, 2005.

[8] J. Osborne, J. W. Osborne, A. B. Costello, and J. T. Kellow, Best Practices in Exploratory Factor Analysis, no. October. 2011.

[9] P. Flom, "Why eigenvalues are greater than 1 in factor analysis," stats.stackexchange, 2014. https://stats.stackexchange.com/questions/72439/why-eigenv alues-are-greater-than-1-in-factor-analysis.

[10] "Principal Component Analysis 4 Dummies: Eigenvectors, Eigenvalues and Dimension Reduction," George Dallas: UK based Information Engineer/Internet Social Scientist. https://georgemdallas.wordpress.com/2013/10/30/principal-c omponent-analysis-4-dummies-eigenvectors-eigenvalues-and -dimension-reduction/.

[11] "How to do an EFA - statwiki Website." http://statwiki.kolobkreations.com/index.php?title=Explorato ry_Factor_Analysis. 